\title{
Biochemical, Anti Microbial and Organoleptic Studies on Rajgira (Amaranthus Caudatus).
}

\author{
*Dr. Jyoti D. Vora, **Ms. Priyanka Jadhav and Ms. Ashwini Rane \\ * Guide Head of Department of Biochemistry and Food Science and Quality control Ramnarain Ruia College, \\ Matunga, Mumbai 19 \\ **Presenting authors, Department of Biochemistry \& Food Science \& Quality Control Ramnarain Ruia \\ College, Matunga, Mumbai 19
}

\begin{abstract}
Pseudocereals are broadleaf plants (non-grasses) that are used in much the same way as cereals (true cereals are grasses). Amaranth has been cultivated as a grain for 8,000 years. It was a staple food of the Aztecs, and was used as an integral part of Aztec religious ceremonies. Seeds of pseudo cereal plant species Amaranthus cauadtus was chosen for the study of germination profile and comparision study was done with a Cereal plant species Wheat. Amaranth is a highly nutritious and non-allergenic crop with remarkable nutraceutical properties.

To substantiate this, the proximate profiles of Carbohydrate, Minerals, Protein and Crude fibers were analyzed over Ohour, 4hours, 6hours, 8hours, 12hours, and 24hours of germination and was compared with Ohours Wheat. The study showed a linear increase in Protein, Calcium, Phosphorous and Iron. The simultaneous reduction in Carbohydrate content indicates that many carbohydrate molecules are broken down during sprouting to allow absorption of atmospheric nitrogen and reforming into amino acids. The Crude Fiber concentration showed varying results.

Anti microbial activity was performed on Ohr and $24 \mathrm{hr}$ germinated sample of Rajgira against Salmonella Typhi. The experiment undertaken confirmed the antimicrobial activity of the aqueous extracts of germinated and nongerminated Amaranthus seeds. Encouraging results were obtained to conclude that pseudo cereals are rich in all proximate values as compared to the cereal. In order to project the organoleptic appeal of the nutritive sprouts under study, invasive and non-invasive sensory evaluation was carried out by a semi- trained panel. This was executed with a recipe of Amaranthus and wheat, one of wheat flour and other of germinated amaranthus. The data was subjected to Biostatistical analysis which proved the recipe of germinated sample of Rajgira was accepted.

The commercial appeal of the sprouts were also speculated using value for money (VFM) studies. The germinated and sprouted variations of pseudo cereal is better in nutritional, sensory as well as commercial aspects.
\end{abstract}

Key words: Pseudocereals, Nutraceutical, Proximate Analysis, Antimicrobial activity, Organoleptic analysis, VFM.

\section{Introduction:}

The nutritional value of pseudocereals is mainly connected to their proteins that are important group of biomacromolecules involved in physiological function. Examples of pseudocereals are amaranth (Love-liesbleeding, red amaranth, Prince-of-Wales-feather), quinoa, and buckwheat. The name 'Amaranth' itself comes from the Latin root word 'amar', meaning long-lived. Amaranthus was a major crop for the Pre-Colombia cultures in Latin America. After the Spanish conquest, its consumption and cultivation was suppressed and thereafter only continued in a small scale. Since it was recognized that amaranthus showed good nutritional properties, the interest in this grain has risen again. According to the literature, the protein content is $14.0-$ $16.5 \%$ for amaranthus and compare to common cereals grain, the protein content of wheat is $14.30 \%$. The important characteristics about amaranthus is that it is gluten free, an advantage for those who have problem in digesting gluten which is present in wheat.

\section{Significance Of Research:}

Amaranth is a grain that is becoming rapidly popular. Amaranth seeds is a well known grain that has many nutritious benefits, non-allergenic crop and is also used in the ayurvedic medicine for treating many disorders with remarkable "Nutraceutical Properties".

Though amaranth is called a grain, the plant it grows on is actually an herb. Amaranth is a healthy grain often used as an alternative to gluten-rich grains. As amaranth is gluten free, it is a great replacement grain for all people who suffer from any form of gluten intolerance, especially those who suffer from celiac disease. 
Amaranth oil with tocotrienol and squalene has potential in medicinal foods. Amaranth oil has antibacterial, anti-tumor, and burn and wound-healing properties. Amaranthus oil also lowers blood serum cholesterol.

Amaranth is an excellent source of protein which contains those amino acids that are usually found only in animal foods. It is loaded with fiber, iron, calcium, vitamins and minerals, and is significantly more nutritious than whole wheat. It is also the best plant source of squalene, a powerful antioxidant used as a dietary supplement for diabetics and those suffering from hypertension and metabolic disorders. Amaranthus seeds is the perfect example of the nutraceutical.

\section{Aim And Objectives:}

Keeping the importance of Amaranthus in mind, the project has been executed with the following aims:

* To study the Biochemical changes during germination of Amaranthus seeds and compare it with wheat grains and to execute a proximate analysis of the same.

* Thus proving, that amaranthus is rich in protein but also rich in other nutritional factors when compared to wheat grains.

* To carry out a Sensory Evaluation to study the socio-culture and Organoleptic acceptance of Amaranthus.

* To compare antimicrobial activity of Non germinated and 24 hour germinated Amaranthus seeds.

\section{Plan Of Work:}

\section{1) Analysis of Proximate Principle:}

Dry (0hr germination), 4hr, 6hr, $8 \mathrm{hr}, 12 \mathrm{hr}, 24 \mathrm{hr}$ germinated samples of Amaranthus seed were selected for comparison with dry Wheat.

The following proximate principles were estimated by performing the experiments named as under:

* Estimation of Proteins by Folin Wu method.

* Estimation of Carbohydrates by Anthrone method.

* Estimation of Crude Fiber.

* Estimation of Calcium by EDTA method.

* Estimation of Iron by Wong's method.

* Estimation of Phosphorous by Fiske-Subbarow method.

* Estimation of Vitamin C by Volumetric method.

* To compare Anti - microbial Activity of non germinated v/s 24 hr germinated seeds.

2) Organoleptic Analysis:

Sensory evaluation was performed of 2 culinary samples, each with amaranthus seeds and wheat grains respectively.

\section{1) Estimation of proximate principles}

\section{Results:}

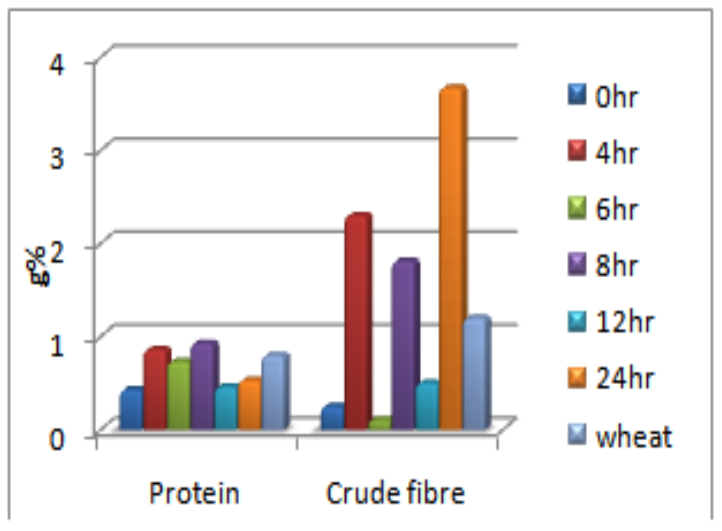




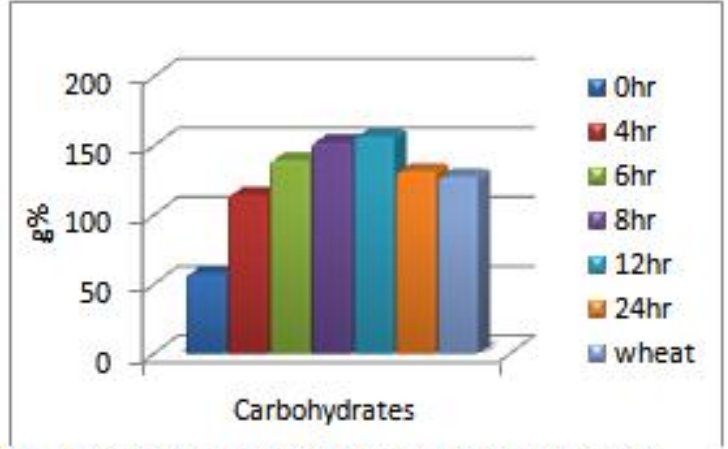

2) Estimation of minerals and vitamin content
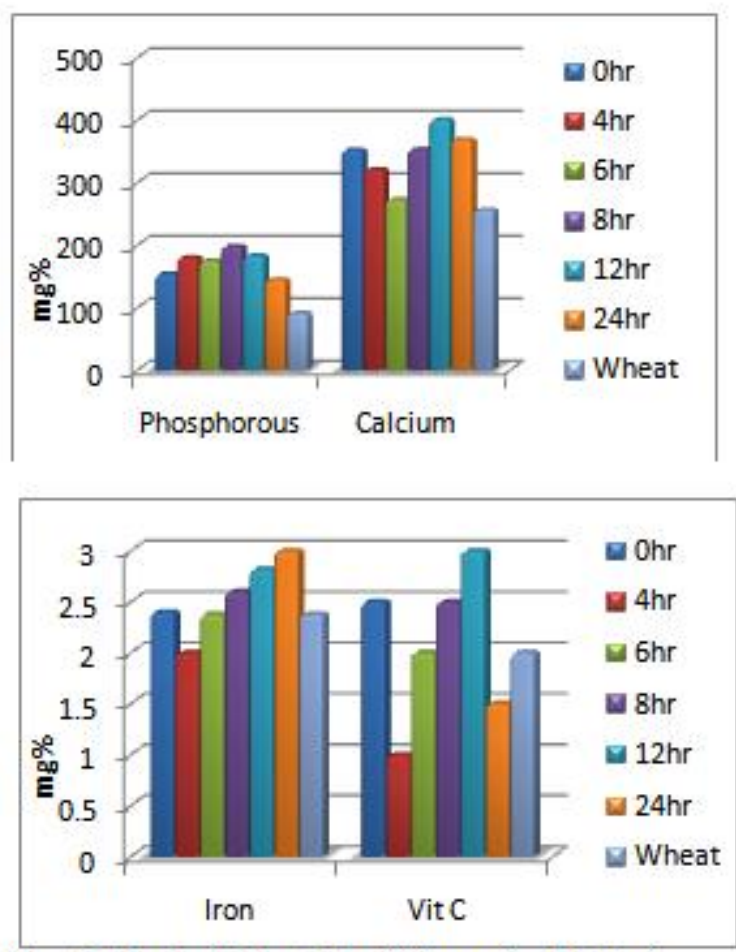

3) Anti-microbial activity (Salmonella Typhus):

a) Non-germinated Amaranthus seed

\begin{tabular}{|l|l|}
\hline Concentration $(\mathbf{m g} / \mathbf{m l})$ & Inhibition \\
\hline 70 & ++++ \\
\hline 140 & +++ \\
\hline 210 & ++ \\
\hline 280 & + \\
\hline 350 & - \\
\hline Positive Control & + \\
\hline Negative Control & - \\
\hline Medium Control & - \\
\hline
\end{tabular}

b) Germinated amaranthus seeds (24hrs)

\begin{tabular}{|l|l|}
\hline Concentration $(\mathbf{m g} / \mathbf{m l})$ & Inhibition \\
\hline 50 & ++++ \\
\hline 100 & +++ \\
\hline 150 & ++ \\
\hline 200 & + \\
\hline 250 & - \\
\hline Positive Control & + \\
\hline Negative Control & - \\
\hline Medium Control & - \\
\hline
\end{tabular}


2) Real Time Pcr:

a) Samples treated with aqueous extracts of non-germinate amaranthus seeds:-

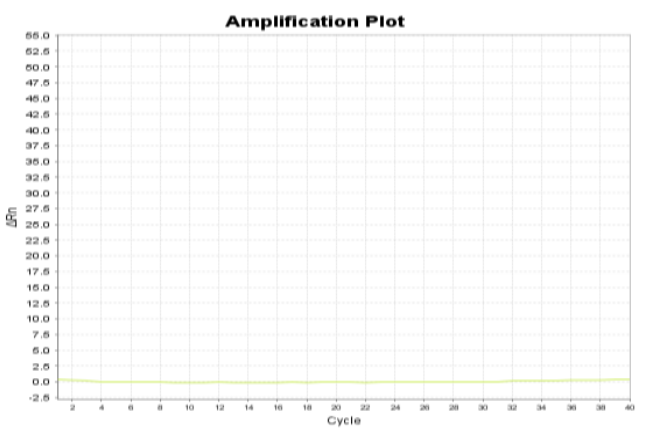

Endogenous control gene

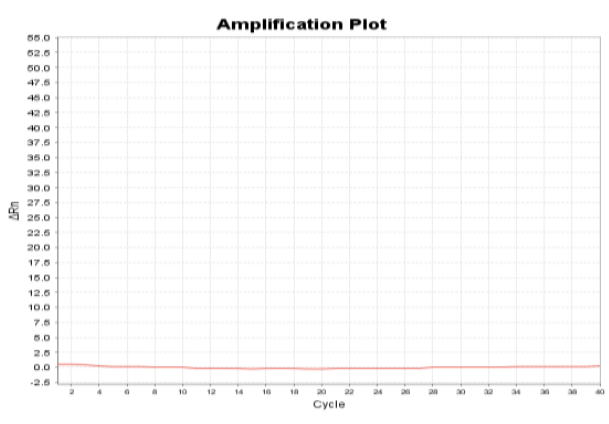

reference gene

b) Samples treated with aqueous extracts of germinate amaranthus seeds:-

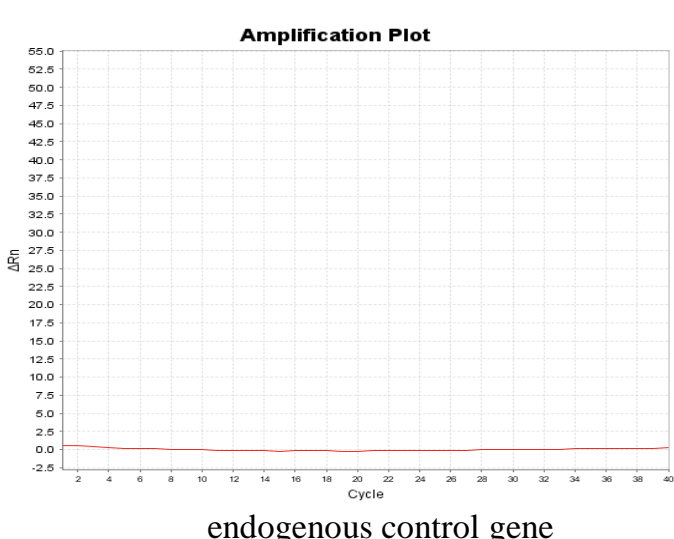

endogenous control gene

a) Untreated Sample

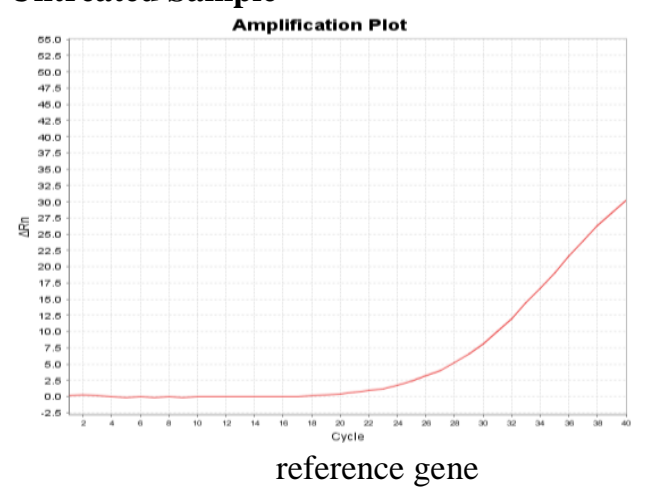

b) Non- template Control

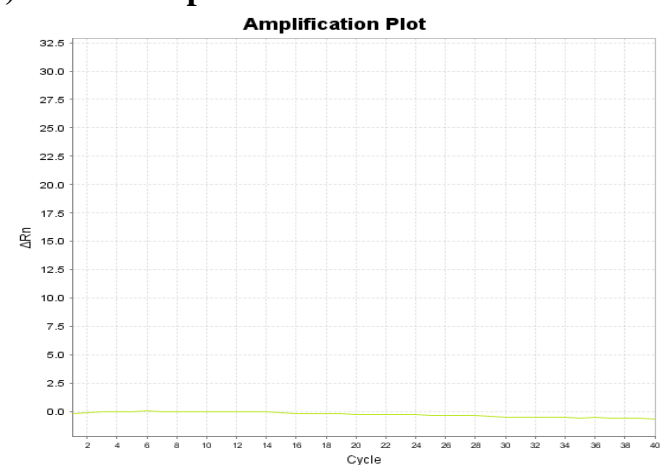

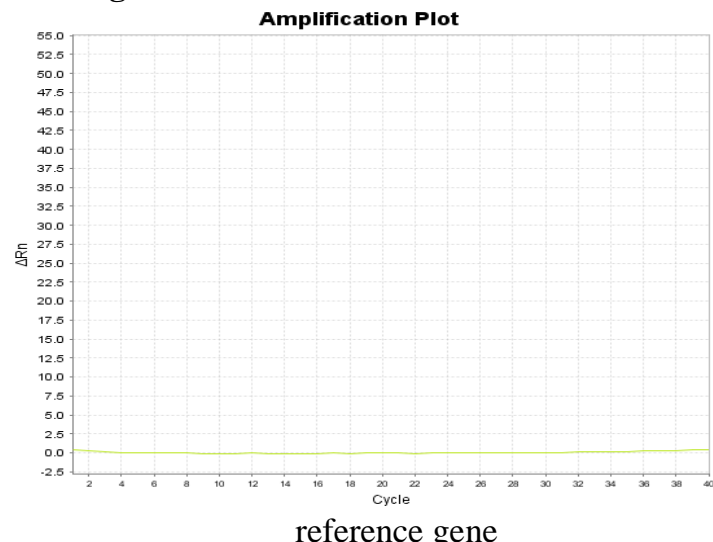

reference gene

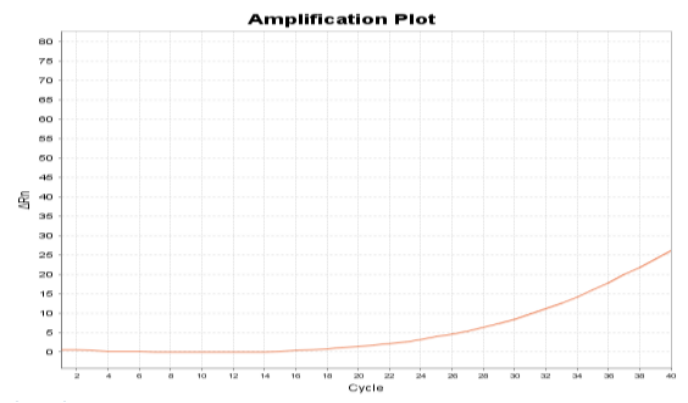

endogenous control gene

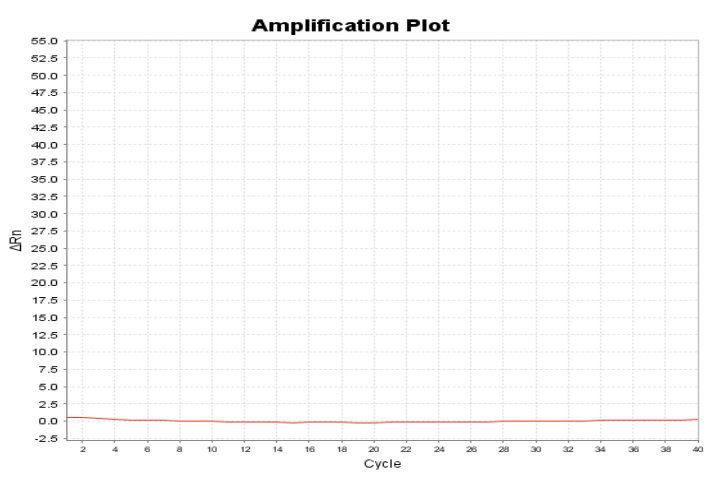

reference gene endogenous control gene 


\begin{tabular}{|l|l|l|}
\hline Sample & $\begin{array}{l}\mathrm{Ct} \\
\text { (reference gene) }\end{array}$ & $\begin{array}{l}\mathrm{Ct} \\
\text { (endogenous control) }\end{array}$ \\
\hline Untreated & 21.09 & 21.94 \\
\hline Treated (non-germinated) & Undetermined & Undetermined \\
\hline Treated (germinated) & Undetermined & Undetermined \\
\hline
\end{tabular}

3) Organoleptic analysis:

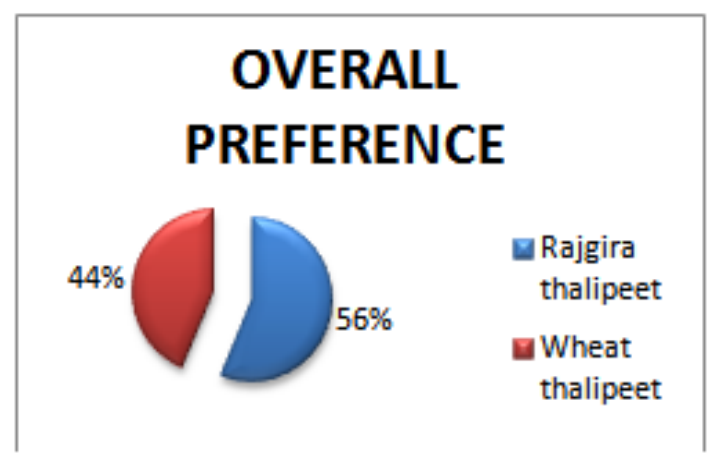

\section{Conclusion:}

The study showed a linear increase in Proteins, Carbohydrates, Calcium, Iron and Vitamin C content with time of germination. The results also showed that Amaranthus has high nutritional content compared to Wheat.

MIC was performed and the result confirmed the antimicrobial activity of the aqueous extracts of germinated and non-germinated amaranthus seeds. The extract has presence of a bactericidal compound which was evident from the results obtained using RT-PCR. The non germinated and germinated had no difference in their anti microbial activity. Therefore aqueous extracts of germinated and non-germinated amaranthus seeds have an effective antimicrobial activity against severe gastro-intestinal tract pathogens such as Salmonella typhi. Encouraging result were obtained to conclude that pseudo cereals are high in all nutritional content compared to cereals(wheat). The results follow that the process of germination promotes the overall metabolic activity in Amaranthus seeds.

\section{Bibliography}

\section{Reference:}

[1]. Biochemical methods, $2^{\text {nd }}$ edition,

[2]. Dr. S. Sadasivam, A Manickam

[3]. New Age International Publication

[4]. Research Methodology: Methods and Techniques, $2^{\text {nd }}$ Edition

[5]. Dr. C. Kothari

[6]. New Age International Publication

[7]. Laboratory Manual T. Y BSc. Biochemistry \& MSc. Biochemistry Department Of Biochemistry and Food Science \& Quality Control

\section{Wibliography}

[8]. en.wikipedia.org/wiki/Amaranth

[9]. www.hort.purdue.edu/newcrop/afcm/amaranth.

[10]. www.seedaholic.com/amaranthus-caudatus-drooping-love-lies-bleeding

[11]. onlinelibrary.wiley.com

[12]. jrr.oxfordjournals.org/content/46/2/233.short 